\title{
Correction to: Hemiarthroplasty for neck of femur fractures: to cement or not? A systematic review of literature and meta-analysis
}

\author{
Prasoon Kumar $^{1}$ (I) $\cdot$ Rajesh Kumar Rajnish $^{1} \cdot$ Deepak Neradi $^{1} \cdot$ Vishal Kumar $^{1} \cdot$ Saurabh Agarwal $^{1} \cdot$ Sameer Aggarwal $^{1}$
}

Published online: 10 July 2019

○) Springer-Verlag France SAS, part of Springer Nature 2019

\section{Correction to: \\ European Journal of Orthopaedic Surgery \& Traumatology (2019) 29:731-746 https://doi.org/10.1007/s00590-019-02364-z}

The original version of this article unfortunately contained a mistake. The correct information is given below.

In abstract, the last sentence of the "Primary outcomes" section should read as:

Mortality at 1 year was the same in both the groups.

The second paragraph of the "Mortality" section should read as:

We meta-analysed four studies that reported mortality at 1 year $[9,14,15,17]$. In cemented group, there were 85 deaths out of 319 , and in uncemented group, there were 87 deaths out of 340 . Analysis showed both the groups to be equivalent [odds ratio 1.07 (95\% CI $0.75-1.52$ and $p=0.71$ )] (Fig. 9). This shows that there is no significant difference in the rates of mortality even if cement is used in hemiarthroplasty, further advocating its usage. So 1-year mortality after all may not be such a big consideration to avoid cemented surgeries and prefer uncemented ones.

The last sentence of the "Re-operation rate" section should read as:

Our analysis showed both groups to be equivalent [odds ratio 0.85 (95\% CI 0.41-1.76)] (Fig. 10).

The seventh paragraph of the "Discussion" section should read as:

In terms of mortality at 1 year, the results were equivocal, showing that use of cement may not be after all a hindrance to survival post-hemiarthroplasties. In terms of other
The original article can be found online at https://doi.org/10.1007/ s00590-019-02364-z.
Saurabh Agarwal saurabh_agr007@yahoo.co.in

Sameer Aggarwal drsameer35@yahoo.co.in

1 Department of Orthopaedics, Post Graduate Institute of Medical Education and Research, Sector-12, Chandigarh 160012, India 
secondary outcomes, there was no difference between the groups.
Publisher's Note Springer Nature remains neutral with regard to jurisdictional claims in published maps and institutional affiliations.

The presentation of Fig. 9 was incorrect. The corrected

Fig. 9 is given below.

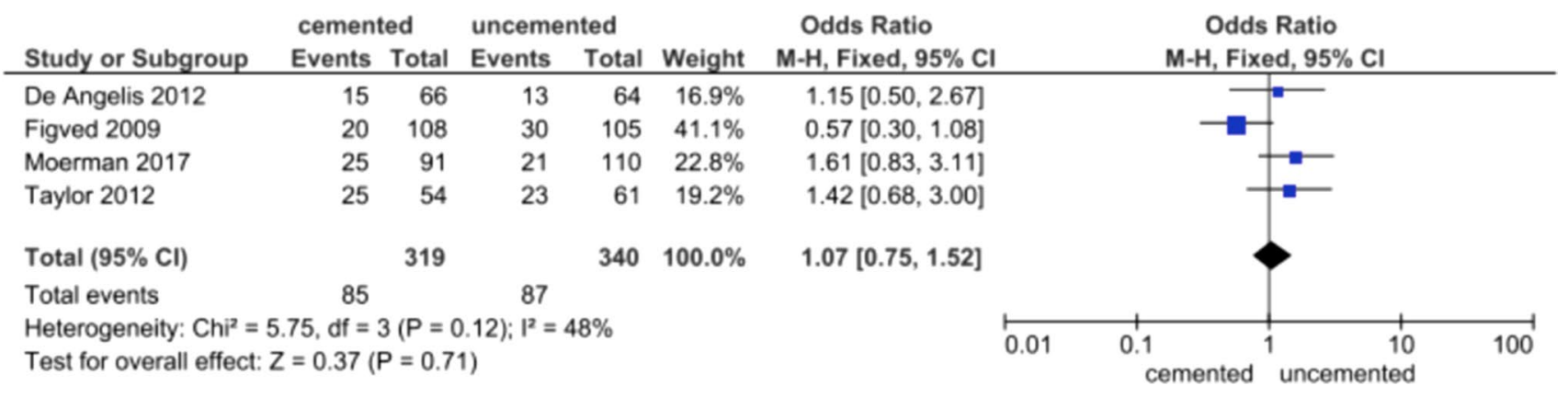

Fig. 9 Difference in mortality at 1 year 